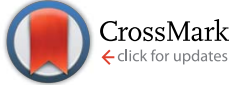

Cite this: RSC Adv., 2017, 7, 2081

Received 11th October 2016 Accepted 30th November 2016

DOI: $10.1039 / c 6 r a 25027 k$

www.rsc.org/advances

\section{Facile one-pot synthesis of magnetic nitrogen- doped porous carbon for high-performance bilirubin removal from BSA-rich solution}

\author{
Chun-Fang Ma, ${ }^{a}$ Qiang Gao, ${ }^{\text {a }}$ Jing Zhou, ${ }^{a}$ Qi-Xuan Chen, ${ }^{a}$ Bo Han, ${ }^{b}$ Kai-Sheng Xia ${ }^{b}$ \\ and Cheng-Gang Zhou*b
}

The development of high-performance adsorbents for efficient removal of bilirubin from albumin-rich solution is still a considerable challenge. In this study, a magnetic nitrogen-doped porous carbon (m$\mathrm{NpC}$ ) was facilely synthesized through a simple one-pot route using the biomass chitosan and the iron salt $\mathrm{Fe}\left(\mathrm{NO}_{3}\right)_{3} \cdot 9 \mathrm{H}_{2} \mathrm{O}$ as precursors, and $\mathrm{NaCl}$ as template agent, respectively. Intriguingly, the resulting $\mathrm{m}$ $\mathrm{NpC}$ material showed a hierarchically micro-meso-macroporous structure, high surface area $\left(289 \mathrm{~m}^{2}\right.$ $\mathrm{g}^{-1}$ ), large pore volume $\left(0.33 \mathrm{~cm}^{3} \mathrm{~g}^{-1}\right)$, and good magnetic response. In particular, the basic site-rich surface of $\mathrm{m}-\mathrm{NpC}$ obtained as a result of nitrogen doping could compete effectively with albumin for bilirubin binding. As such, the $\mathrm{m}-\mathrm{NpC}$ was used as a magnetically separable bilirubin adsorbent and showed superior adsorption properties for bilirubin removal from a bovine serum albumin (BSA)-rich solution. Under optimized conditions, the maximum adsorption capacity of $\mathrm{m}-\mathrm{NpC}$ was up to $72.4 \mathrm{mg}$ $\mathrm{g}^{-1}$, which is significantly higher than the value achieved by magnetic non-nitrogen doped porous carbon (24.7 $\mathrm{mg} \mathrm{g}^{-1}$ ), but also superior to those of many previously reported adsorbents for BSA-boned bilirubin removal. Moreover, as evidenced by hemolysis assay, this material exhibited only a negligible hemolysis effect. These results suggest that the composite developed in this work can be used as a promising adsorbent in blood purification application to mitigate the risk of excess bilirubin.

\section{Introduction}

Bilirubin, one of the breakdown products of hemoglobin, is a typical toxin and generally transported on the blood circuit as a complex with serum albumin. ${ }^{1}$ In a healthy human body, the concentration of bilirubin in the blood is basically kept at a relatively constant level. However, when the liver's function is impaired, the bilirubin cannot be adequately excreted and thus accumulates in the organism. ${ }^{1}$ The presence of excess bilirubin may cause hepatitis, jaundice, brain damage, and even death in severe cases. ${ }^{2}$ Many techniques, such as hemodialysis, phototherapy, and hemoperfusion, have therefore been applied to remove bilirubin from hyperbilirubinemic human plasma for reducing bilirubin level to normal range. ${ }^{3}$ Among them, hemoperfusion is the preferred technique that can directly remove bilirubin by passing patient's blood over a solid adsorbent. ${ }^{4}$

To date, a considerable number of haemoperfusion systems employ carbon-based materials as the adsorbents because of

${ }^{a}$ Department of Chemistry, Faculty of Material Science and Chemistry, China University of Geosciences, Wuhan 430074, PR China.E-mail: gaoqiang@cug.edu.cn; Fax: +860276788 3731; Tel: +8602767883731

${ }^{b}$ Sustainable Energy Laboratory, Faculty of Material Science and Chemistry, China University of Geosciences, Wuhan 430074, PR China.E-mail: cgzhou@cug.edu.cn their intrinsic properties such as excellent stability, inertness, high blood compatibility, and being capable of providing multiple interactions (e.g., hydrophobic and $\pi-\pi$ interactions) for bilirubin adsorption. ${ }^{5}$ Taking into account the crucial contribution of specific surface area and porosity to adsorption performance, current research interest mainly focuses on the development of high-surface-area porous carbon-based haemoperfusion adsorbents including activated carbon, ${ }^{6}$ carbon nanotube, ${ }^{7-9}$ mesoporous carbon, ${ }^{\mathbf{1 0}}$ hollow carbon spheres, ${ }^{\mathbf{1 , 1 1}}$ and porous carbon monolith ${ }^{\mathbf{1 2}}$ etc. However, it should be noted that these experiments of bilirubin adsorptions on various pure porous carbons are mostly conducted in albumin-free solution, which is contrary to the facts that serum albumin is the most abundant protein in blood and bilirubin exists primarily in the form of albumin-bilirubin complex. ${ }^{\mathbf{1 3 - 1 5}}$ Despite the advantage of high effectiveness for free bilirubin removal, these pure porous carbon adsorbents usually perform poorly on the removal of albumin-bonded bilirubin. For instance, the reported adsorption capacity of carbon nanotube sheets toward bovine serum albumin (BSA)-bonded bilirubin is $9.7 \mathrm{mg} \mathrm{g}^{-1}$, which is significantly lower than the values obtained for free bilirubin removal. ${ }^{8}$

In order to enhance removal effectiveness for albuminbonded bilirubin, the most popular strategy is to integrate porous carbon and organic polymer (e.g., chitosan) into a single 
adsorbent. In this direction, a number of carbon/polymer composites, such as chitosan encapsulated activated charcoal, ${ }^{\mathbf{1 6}}$ carbon nanotube/chitosan composite beads, ${ }^{17}$ and heparinmodified chitosan/graphene oxide hybrid hydrogel, ${ }^{4}$ have been prepared and tested for adsorptive removal of free and/or albumin-bonded bilirubin. However, although some progress has been made, there still exist some obstacles to use these adsorbents for blood purification. For example, the polymer molecules can penetrate the pores of porous carbon and cause a significant decrease of porosity or even a complete pore blocking. ${ }^{18}$ Moreover, in most cases the porous carbon particles are essentially encapsulated into the polymer network, leading to a difficult access of bilirubin to carbon surface. ${ }^{18}$ As a consequence, the contribution of porous carbon to the bilirubin adsorption is slight or negligible. Therefore, further investigation is still needed regarding the different possibilities of porous carbon functionalization for albumin-bonded bilirubin removal.

In fact, the doping of a heteroatom into the carbon skeleton is an effective method for the functionalization of carbons. ${ }^{19}$ Unlike the polymer incorporating, the heteroatom doping can tailor the surface property of porous carbon, while avoiding the pore blocking and/or the surface coverage. ${ }^{20}$ Over the past few years, a variety of heteroatom (e.g., silicon, boron, phosphorus, or nitrogen $e t c$.)-doped carbons have been synthesized and used in various applications. ${ }^{21-24}$ Among them, the nitrogen-doped carbon is of particular interest due to its unique basic sitesrich surface, which can provide high affinity for capture of acidic molecules or metal ions. ${ }^{\mathbf{2 3 , 2 5 , 2 6}}$ For example, Fan et al. reported the synthesis of a nitrogen-doped porous carbon by using chitosan as a precursor and confirmed its excellent performance in $\mathrm{CO}_{2}$ capture. ${ }^{27}$ Nevertheless, little work has been done on the development of nitrogen-doped carbonsbased adsorbents for albumin-bonded bilirubin removal. Keeping in mind the unique features of nitrogen-doped carbon (e.g., basic sites-rich surface) and the molecular characteristics of bilirubin (e.g., dicarboxylic acid-functional structure), we speculate that nitrogen-doped carbon might be capable of competing effectively with albumin for bilirubin binding so as to be suited for further application in removal of albuminbonded bilirubin.

On the other hand, magnetic nanoparticles supported on porous carbon materials have been intensively pursued for emerging applications in drug delivery, catalysis, and adsorption. ${ }^{28}$ Very recently, several magnetic porous carbons have been also prepared and applied to bilirubin removal. ${ }^{7,11,29}$ Indeed, these novel adsorbents combine the features of porous carbons and magnetic nanoparticles, exhibiting certain advantages, especially in adsorbent recovery after bilirubin removal. However, in these reports, the magnetic porous carbons are generally fabricated by adopting multi-step experimental processes, which are usually expensive and time-consuming with a relatively low yield. Moreover, while efforts have been concentrated on the adsorption of free bilirubin from solution by employing magnetic porous carbons as adsorbents, the treatment capacity in some special conditions, such as adsorption solutions containing abundant albumin, still needs to be further promoted.
According to the above considerations, it is rationally expected to doubly improve the features of porous carbon by introducing nitrogen atoms into carbon skeleton, and simultaneously incorporating with magnetic nanoparticles to enhance and extend its function and applications. For this purpose, herein we report the successful synthesis of a magnetic nitrogen-doped porous carbon (m-NpC) through a simple onepot route using chitosan and $\mathrm{Fe}\left(\mathrm{NO}_{3}\right)_{3} \cdot 9 \mathrm{H}_{2} \mathrm{O}$ as precursors, and $\mathrm{NaCl}$ as template agent, ${ }^{30}$ respectively. It was found that the resulting $\mathrm{m}-\mathrm{NpC}$ showed a hierarchical and nitrogen-rich structure, high surface area $\left(289 \mathrm{~m}^{2} \mathrm{~g}^{-1}\right)$, large pore volume (0.33 $\left.\mathrm{cm}^{3} \mathrm{~g}^{-1}\right)$, and good magnetic responsibility. More importantly, the as-prepared $\mathrm{m}-\mathrm{NpC}$ was tested as the adsorbent for bilirubin removal from BSA-rich solution, where a high adsorption capability toward albumin-bonded bilirubin as well as good hemocompatibility could be implemented.

\section{Experimental}

\subsection{Raw material and chemicals}

Bilirubin was obtained from Hubei Bangsheng Chemicals Co., Ltd. (Wuhan, China). The albumin from bovine serum (BSA, $M_{\mathrm{w}}$ $=67000)$ and hydrochloric acid ( $\mathrm{HCl}, 37 \%)$ were purchased from Sinopharm Chemical Reagent Co., Ltd. (Shanghai, China). Chitosan $\left(M_{\mathrm{w}} \cong 1000\right.$, deacetylation degree $\left.>90 \%\right)$, a water-soluble polysaccharide comprising copolymer of glucosamine and $\mathrm{N}$ acetylglucosamine, was purchased from Yuhuan Shell Biological Agents Factories (Zhenjiang, China). Analytically pure ethanol, $\mathrm{Fe}\left(\mathrm{NO}_{3}\right)_{3} \cdot 9 \mathrm{H}_{2} \mathrm{O}, \mathrm{NaCl}$, and $\mathrm{NaOH}$ were all obtained from Sinopharm Chemical Reagent Co., Ltd. (Shanghai, China). All chemicals and regents used in this study were commercially available and used without further purification. Distilled water was used throughout the experiments for solution preparation.

\subsection{Preparation of $\mathrm{m}-\mathrm{NpC}$}

The m-NpC was synthesized through one-pot route by referring to a previously reported procedure for synthesis of magnetic porous carbon (without nitrogen doping), ${ }^{31}$ where the glucose was used as the carbon precursor. In our synthesis, the biomass chitosan was used as the co-precursor of carbon and nitrogen. Typically, metal precursor $\left(\mathrm{Fe}\left(\mathrm{NO}_{3}\right)_{3} \cdot 9 \mathrm{H}_{2} \mathrm{O} ; 0.73 \mathrm{~g}\right)$, coprecursor (chitosan; $2 \mathrm{~g})$, and template agent $(\mathrm{NaCl} ; 15 \mathrm{~g}$ ) were dissolved in $45 \mathrm{~mL}$ of water. The resulting homogenous solution was dried and then ground to obtain very fine powders. Afterwards, the powders were heated at $750{ }^{\circ} \mathrm{C}$ for $2 \mathrm{~h}$ in a tube furnace under $\mathrm{N}_{2}$ protection and then annealed at $250^{\circ} \mathrm{C}$ for $6 \mathrm{~h}$ under air. Once cooled to room temperature, the obtained powders were treated with water repeatedly to completely remove $\mathrm{NaCl}$, and then the target product $\mathrm{m}-\mathrm{NpC}$ was obtained. For comparison, magnetic non-nitrogen doped porous carbon (m-pC) was also synthesized according to a similar procedure with the use of glucose ( $2 \mathrm{~g}$ ) as carbon precursor.

\subsection{Characterization of materials}

Powder X-ray diffraction (XRD) pattern of the as-synthesized mNpC was recorded on a Bruker AXS D8-FOCUS diffractometer 
using monochromatized $\mathrm{Cu}-\mathrm{K} \alpha$ radiation $(\lambda=0.1540598 \mathrm{~nm})$. Apparent porous characteristic and morphology of the m-NpC were observed by scanning electron microscopy (SEM, Hitch SU8010) and transmission electron microscopy (TEM, Philips CM12). Raman spectrum was recorded using a Horiba JobinYvon LabRAM HR800 Raman microspectrometer. Specific surface area assessment and pore distribution measurements were carried out by $\mathrm{N}_{2}$ adsorption/desorption analysis at $77 \mathrm{~K}$ using a Micromeritics ASAP 2020 HD88 system. X-ray photoelectron spectroscopy (XPS) measurements were performed in a VG Scientific ESCALAB Mark II spectrometer equipped with two ultra-high vacuum (UHV) chambers to evaluate the chemical states of constituent elements. Magnetic hysteresis loop was measured on a vibrating sample magnetometer (VSM, Lakeshore 7400) at room temperature.

\subsection{Adsorption toward BSA-bonded bilirubin}

To evaluate the adsorption properties of $\mathrm{m}-\mathrm{NpC}$, a stock solution composed of a certain amount of bilirubin and $40 \mathrm{~g} \mathrm{~L}^{-1}$ BSA was prepared instead of hyperbilirubinemia patient's plasma. Typically, bilirubin powders were dissolved in a $\mathrm{NaOH}$ solution $\left(0.1 \mathrm{~mol} \mathrm{~L}^{-1}\right)$, and then the solution was mixed with BSA solution, where the final $\mathrm{pH}$ was adjusted to 7.4 to simulate the blood $\mathrm{pH}$ environment. In light of the high sensitivity of bilirubin to light, all adsorption experiments were conducted in dark. Typical adsorption procedure was performed as follows: $3 \mathrm{mg}$ of $\mathrm{m}-\mathrm{NpC}$ were added into a glass bottle that contained 10 $\mathrm{mL}$ of BSA-bonded bilirubin solution $\left(300 \mathrm{mg} \mathrm{L}^{-1}\right)$, then the mixture was shaken with speed of $200 \mathrm{rpm}$ in a shaker at $37{ }^{\circ} \mathrm{C}$ for about $2 \mathrm{~h}$. After that, the bilirubin-adsorbed m-NpC were magnetically separated from the solution by an external magnet. Adsorption capacity of bilirubin was determined by using the UV-vis spectroscopy at a wavelength of $461 \mathrm{~nm}$, and its value was calculated according to the following equation: $Q_{\mathrm{e}}=$ $V\left(C_{0}-C_{\mathrm{e}}\right) / m$, where $Q_{\mathrm{e}}$ is the equilibrium adsorption capacity $\left(\mathrm{mg} \mathrm{g}^{-1}\right), C_{0}$ and $C_{\mathrm{e}}$ are the initial and equilibrium concentrations $\left(\mathrm{mg} \mathrm{L}^{-1}\right)$, respectively, $V$ is the volume of adsorption solution (L), and $m$ is the mass of the added adsorbent $(\mathrm{g})$.

In order to examine the adsorption rate and kinetic characteristics, three sets of kinetic experiments were performed by controlling the contact time from 10 to $165 \mathrm{~min}$ at a fixed initial BSA-bonded bilirubin concentration $\left(300 \mathrm{mg} \mathrm{L}^{-1}\right)$ under three different temperatures $\left(25,30\right.$, and $\left.37{ }^{\circ} \mathrm{C}\right)$, respectively. To reveal the equilibrium adsorption characteristics, three sets of isothermal adsorption experiments were carried out at three different temperatures $\left(25,30\right.$, and $\left.37^{\circ} \mathrm{C}\right)$ over a range of initial BSA-bonded bilirubin concentrations from 50 to $300 \mathrm{mg} \mathrm{L}^{-1}$.

\subsection{Hemolysis assay}

Hemolysis assay was carried out to preliminarily evaluate the blood compatibility of $\mathrm{m}-\mathrm{NpC}$ similar to the reported procedure, ${ }^{1}$ where human blood anti-coagulated with ethylene diamine tetraacetic acid (EDTA) was kindly provided by China University of Geosciences Hospital (Wuhan). In brief, the obtained red blood cells (RBCs) after centrifugation and suction were washed at least three times with phosphate-buffered saline
(PBS, pH 7.4). Afterwards, the cells were diluted to $1 / 10$ of their original volume with PBS for subsequent use. Next, the red blood cells (RBCs) suspensions $(0.3 \mathrm{~mL})$ were mixed with $1.2 \mathrm{~mL}$ of PBS suspensions and different added amount of m-NpC. Both positive and negative controls were tested by mixing 0.3 $\mathrm{mL}$ of RBCs suspensions with $1.2 \mathrm{~mL}$ of pure water or $1.2 \mathrm{~mL}$ of PBS. After completely mixing, the suspension samples were centrifuged, and the absorbance of the supernatant at $541 \mathrm{~nm}$ was recorded by UV-vis spectroscopy. The hemolysis rate was calculated according to the following equation: hemolysis rate $(\%)=\left(A_{1}-A_{3}\right) /\left(A_{2}-A_{3}\right) \times 100 \%$, where $A_{1}, A_{2}$, and $A_{3}$ are the absorbance intensities of the sample, positive control, and negative control, respectively.

\section{Results and discussion}

\subsection{Characterization of materials}

XRD analysis was conducted to obtain phase structure information about the m-NpC from the one-pot synthesis, and the result is shown in Fig. 1a. Clearly, the sample exhibits a broad diffraction peak centered at $2 \theta$ of about $26^{\circ}$ in its XRD pattern, which is characteristic diffraction peak of graphite, ${ }^{32}$ indicating the formation of carbon skeleton through calcination of the biomass precursor (chitosan). The broad diffraction peak suggests poor crystallinity of the carbon. Besides, all the other peaks can be readily indexed to two phases of $\mathrm{Fe}$ and $\mathrm{Fe}_{3} \mathrm{O}_{4}$, which is in agreement with the reported values in the literature. ${ }^{32}$ The formation of $\mathrm{Fe}$ and $\mathrm{Fe}_{3} \mathrm{O}_{4}$ might be explained by the "decomposition-reduction-oxidation" processes occurred in our synthesis. ${ }^{31}$ Specifically, in the first stage $\left(750{ }^{\circ} \mathrm{C} ; \mathrm{N}_{2}\right.$ protection), the metal precursor $\left(\mathrm{Fe}\left(\mathrm{NO}_{3}\right)_{3} \cdot 9 \mathrm{H}_{2} \mathrm{O}\right)$ would be decomposed to iron oxide, and the carbon species from chitosan could reduce the iron oxide to Fe nanoparticle. Subsequently, the sample was exposed to air at $250{ }^{\circ} \mathrm{C}$, the $\mathrm{Fe}$ nanoparticles would be partially oxidized to $\mathrm{Fe}_{3} \mathrm{O}_{4}$. As a consequence, the $\mathrm{Fe}$ and $\mathrm{Fe}_{3} \mathrm{O}_{4}$ are found to exist together in $\mathrm{m}-\mathrm{NpC}$ (Fig. 1a).

To verify the presence of nitrogen in the $\mathrm{m}$-NpC, X-ray photoelectron spectroscopy (XPS) was carried out, and the results are shown in Fig. $1 \mathrm{~b}$ and $\mathrm{c}$. In the $\mathrm{C} 1 \mathrm{~s}$ spectrum, the main peak position of $\mathrm{C} 1 \mathrm{~s}$ at $284.6 \mathrm{eV}$ is attributed to aromatic $\mathrm{C}=\mathrm{C}$ bonds and small signals at 285.9 and $286.8 \mathrm{eV}$ which are attributed to $\mathrm{C}=\mathrm{N}$ and $\mathrm{C}-\mathrm{N}$ species, ${ }^{33}$ respectively (Fig. 1b). As shown in Fig. 1c, the $\mathrm{N}$ 1s spectrum definitely displays the nitrogen species and is deconvoluted into pyridinic-N (398.4 $\mathrm{eV})$, pyrrolic/pyridinic-N (400.4 eV), and graphitic-N $(402.2 \mathrm{eV}) .^{34}$ It is noted that the peak intensities of pyridinic- $\mathrm{N}$ and graphitic$\mathrm{N}$ are significantly weaker than that of pyrrolic/pyridinic- $\mathrm{N}$ (Fig. 1c), implying that pyrrolic nitrogen and pyridinic nitrogen are dominant in the as-prepared material. Judging from these data, we can conclude that the nitrogen has been successfully doped into the carbon skeleton.

The Raman spectrum of the m-NpC is shown in Fig. 1d, and two characteristic peaks centered at approximately 1341 (Dband) and $1588 \mathrm{~cm}^{-1}$ (G-band) are observed. The D-band stands for the disorder-induced mode related to structural defects and imperfections, while the G-band originates from the 
(a)

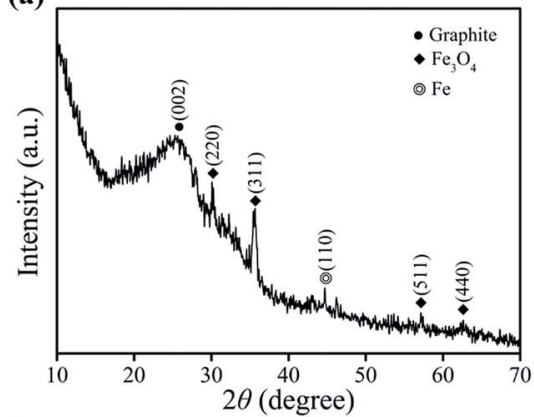

(c)

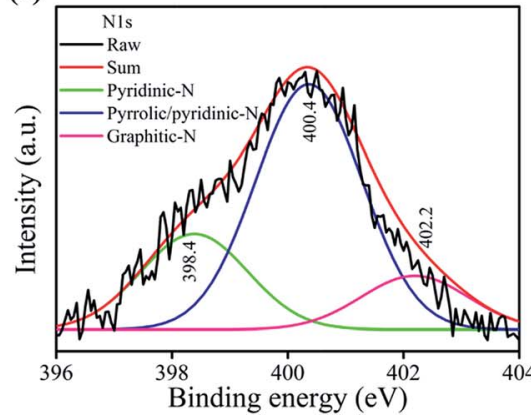

(b)

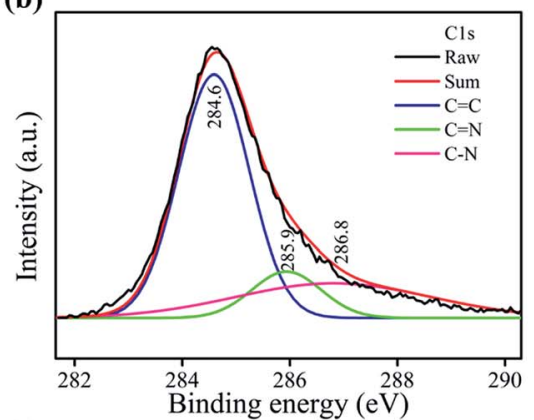

(d)

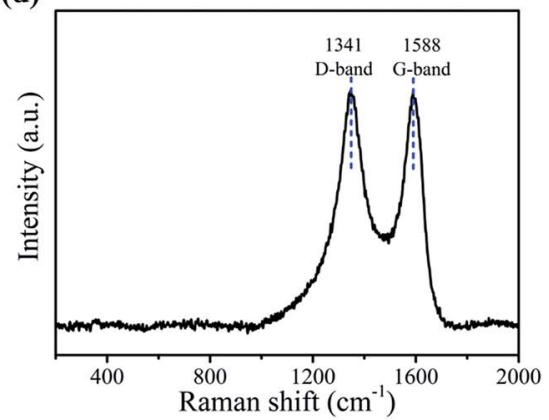

Fig. 1 XRD pattern (a); XPS spectra: C 1s (b) and N 1s (c); Raman spectrum (d).

in-plane vibrations of the $\mathrm{sp}^{2}$ carbon atoms..$^{35}$ As well known, the D-to-G peak intensity ratio $\left(I_{\mathrm{G}} / I_{\mathrm{D}}\right)$ is usually used to estimate the $\mathrm{sp}^{2}$ domain size within graphite-based materials. A high $I_{\mathrm{G}} /$ $I_{\mathrm{D}}$ value indicates a high graphitization degree, and vice versa. ${ }^{36}$ It can be calculated that the $I_{\mathrm{G}} / I_{\mathrm{D}}$ ratio of $\mathrm{m}-\mathrm{NpC}$ is 1.003 . Compared with the results obtained from pure porous carbon in the literature, ${ }^{35}$ the $I_{\mathrm{G}} / I_{\mathrm{D}}$ value of $\mathrm{m}-\mathrm{NpC}$ is slightly low and indicates its relatively low degree of graphitization, which might be attributed to the nitrogen doping into carbon skeleton. ${ }^{37}$

The SEM and TEM images of m-NpC are shown in Fig. 2. As seen from Fig. 2a, the sample is foam-like with slight aggregation. The typical graphene-like sheets can be distinctly observed in Fig. $2 \mathrm{~b}$ with respect to the highly transparent texture and crumpled-sheet morphology, which is consistent with the SEM morphology of previously reported graphene material. ${ }^{36}$ In general, the carbonization of biomass results in the formation of carbon blocks rather than carbon nanosheets. In this work, the addition of a lot of $\mathrm{NaCl}$ might provide sufficient solid surface to direct the formation of chitosan coating, which resulted in the occurrence of a two-dimensional nanostructure after carbonization. Similar results were also found in the literature using glucose and $\mathrm{NaCl}$ as carbon resource and template agent, respectively. ${ }^{31}$ From Fig. $2 \mathrm{a}$ and b, it is also observed that the curved sheets stack together to form a hierarchical structure with visible macropores and mesopores. Such an architecture should have a relatively high surface area due to the hierarchical characteristics and would provide high adsorptive efficiency because of the easy access to its active sites. The structural characterization in further detail was achieved using TEM, as shown in Fig. $2 \mathrm{c}$ and d. Clearly, the produced nitrogen-doped carbon sheet is highly porous (Fig. 2c), which should be due to the release of gaseous species during pyrolysis of chitosan..$^{33}$ Moreover, some partially aligned graphitic layers are also found in the nitrogendoped carbon sheet (Fig. 2d), which is in agreement with XRD result, indicating its graphite-like nature. Interestingly, a lot of magnetic nanoparticles (i.e., $\mathrm{Fe}$ or $\mathrm{Fe}_{3} \mathrm{O}_{4}$ ) with diameter of about 20-30 nm are found to be embedded in the nitrogen-doped carbon skeleton (inset of Fig. 2d). Compared with the common magnetization of porous carbons, i.e., loading magnetic nanoparticles on the surface of porous carbon, such encapsulation of magnetic nanoparticles into the skeleton might be more advantageous to avoid leaching of magnetic species and/or covering the adsorption sites.

The $\mathrm{N}_{2}$ adsorption/desorption isotherms of $\mathrm{m}-\mathrm{NpC}$ are shown in Fig. 3a. It is evident that the m-NpC shows a continuous increased $\mathrm{N}_{2}$ adsorption with a combined feature of type IV and type II isotherms, indicating the co-presence of mesopores and macropores. ${ }^{36}$ Moreover, $\mathrm{H}_{2}$ hysteresis loop at relative pressure $\left(P / P_{0}\right)$ above 0.4 is also clearly observed, indicating its cylindrical pores with nonuniform shape. ${ }^{38}$ Pore size distribution (PSD) of m-NpC obtained by Barrett-Joyner-Halenda (BJH) method displays a strong broad distribution of mesopores centered at about $12.3 \mathrm{~nm}$ and a weak broad distribution of smaller mesopores centered at about $2.1 \mathrm{~nm}$ (Fig. 3b). The detailed texture parameters are calculated and it is found that the $\mathrm{m}-\mathrm{NpC}$ has a surface area of $289 \mathrm{~m}^{2} \mathrm{~g}^{-1}$ and a pore volume of $0.33 \mathrm{~cm}^{3} \mathrm{~g}^{-1}$. In view of the limitation of $\mathrm{BJH}$ method in evaluating micropores, we further used a non-local density functional theory model in order to obtain a continuous PSD in the range of less than $2.0 \mathrm{~nm}$ (inset of Fig. 3b). It is found that the $\mathrm{m}-\mathrm{NpC}$ contains significant micropores locating around 0.6 and $0.8 \mathrm{~nm}$. All of the results from $\mathrm{N}_{2}$ adsorption/desorption measurement confirm that the $\mathrm{m}-\mathrm{NpC}$ possesses a hierarchically micro-meso-macroporous structure with a high porosity. 

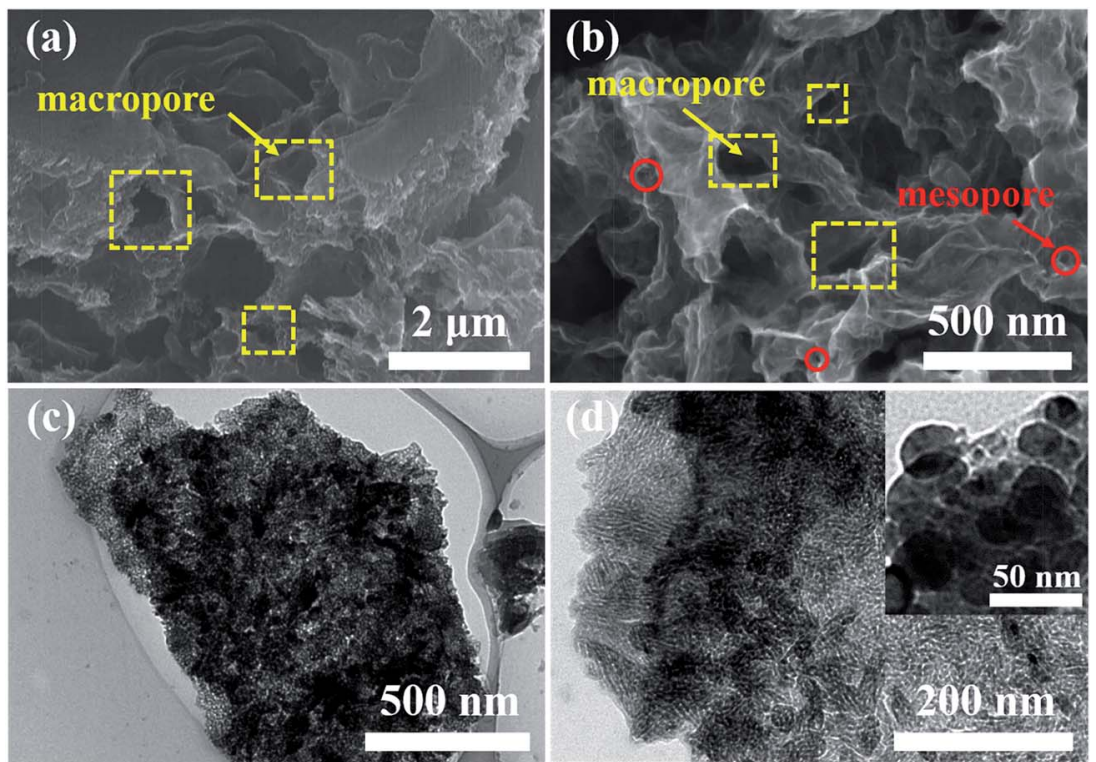

Fig. 2 SEM ( $a$ and $b$ ) and TEM (c and d) images of $\mathrm{m}-\mathrm{NpC}$.

The magnetization curve of $\mathrm{m}-\mathrm{NpC}$ at room temperature shows its characteristic of soft ferromagnetism which demonstrates the strong magnetic response to a varying magnetic field (Fig. 4). ${ }^{11}$ The saturation magnetization value is found to be $7.42 \mathrm{emu} \mathrm{g}^{-1}$, while the coercivity value is 258 Oe as estimated from the bottom inset of Fig. 4. Furthermore, the photographs shown in the top inset of Fig. 4 visually reflect the dispersity of $\mathrm{m}-\mathrm{NpC}$ in water and its magnetic responsibility. Clearly, $\mathrm{m}-\mathrm{NpC}$ can be homogeneously dispersed in water to form a uniform suspension before magnetic separation. However, once a magnet is placed close to the reaction vessel for a while ( $>60 \mathrm{~s})$, it can be observed that the m-NpC particles are rapidly attracted, and a clear solution is formed. After removal of the external magnet, slight agitation can enable the $\mathrm{m}$-NpC particles to be well redispersed in water. The attraction and redispersion processes can be readily altered by switching an external magnetic field, indicating a good water-dispersion and magnetic separation characteristics of $\mathrm{m}-\mathrm{NpC}$ in aqueous medium.

\subsection{Adsorption properties of $\mathrm{m}-\mathrm{NpC}$ towards albumin- bonded bilirubin}

Bilirubin is a tetrapyrrole dicarboxylic acid and has a strong tendency to bind with albumin in the blood to form the albumin-bilirubin complex. ${ }^{1}$ For efficient removal of bilirubin, adsorbent is expected to be capable of competing with albumin for bilirubin binding. As above characterization results demonstrate, the novel m-NpC composite shows a highly porous structure, high surface area, and large pore volume. In particular, as a result of nitrogen-doping, the m-NpC exhibits a basic sites-rich surface, probably making this adsorbent competent for removal of bilirubin from the albumin-rich solution. In addition, the magnetic responsibility of $\mathrm{m}-\mathrm{NpC}$ endows this adsorbent with the advantage of facile separation after bilirubin removal. Thus, we speculated that the $\mathrm{m}-\mathrm{NpC}$ should be an efficient adsorbent for albumin-bonded bilirubin removal. To verify this anticipation, the adsorption behaviors of $\mathrm{m}$-NpC toward BSA-bonded bilirubin were systematically investigated. (a)

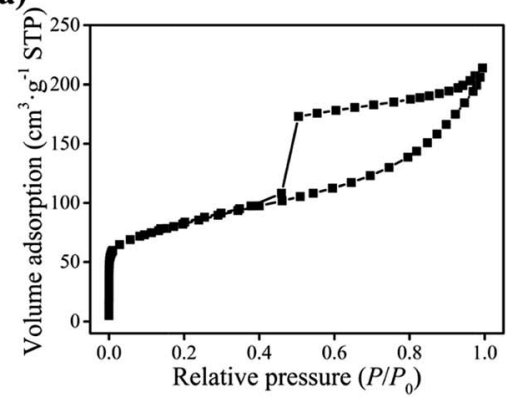

(b)

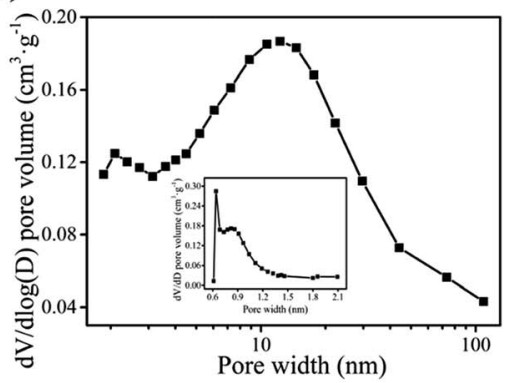

Fig. $3 \mathrm{~N}_{2}$ adsorption/desorption isotherms of $\mathrm{m}-\mathrm{NpC}$ (a), and pore size distribution of $\mathrm{m}-\mathrm{NpC}$ in the range of $2-100 \mathrm{~nm}$ (b). The inset shows the pore size distribution in the range of less than $2 \mathrm{~nm}$. 


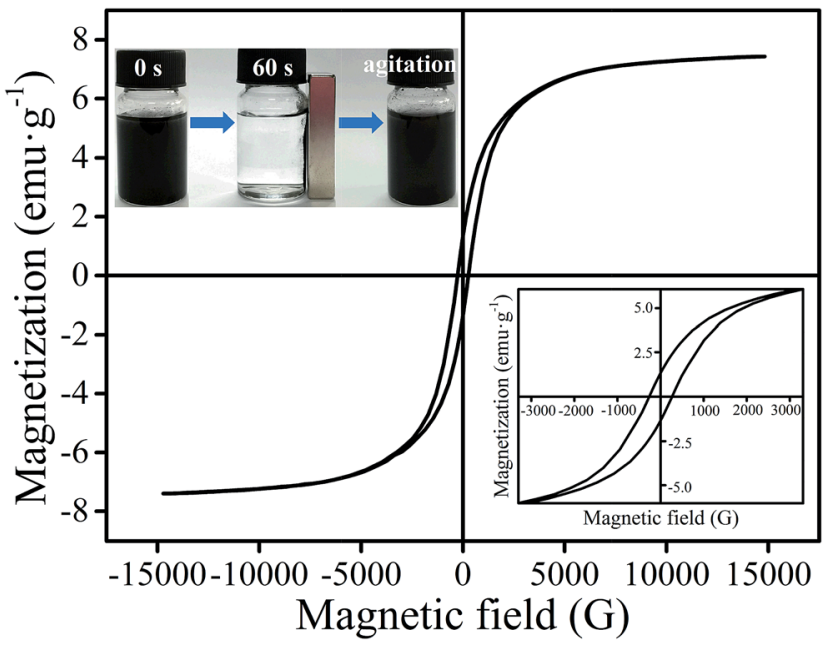

Fig. 4 Magnetic hysteresis loop of $\mathrm{m}-\mathrm{NpC}$ with photographs reflecting the magnetic separability and water dispersity of $\mathrm{m}-\mathrm{NpC}$ (the top inset), where the bottom inset is the partial enlarged view of hysteresis loop.

3.2.1 Adsorption selectivity and the role of nitrogen doping in adsorption. During hemoperfusion, when human plasma flow is passed over a solid adsorbent, both albumin and bilirubin are probably adsorbed on the adsorbent. So, we firstly investigated the adsorption selectivity of $\mathrm{m}-\mathrm{NpC}$ by determining both concentrations of conjugated bilirubin and BSA before and after adsorption. It was found that the concentrations of BSA were nearly unchanged for all these adsorption experiments, indicating that the adsorbent could not effectively adsorb BSA. The finding is consistent with the result of the previous study, in which a negligible adsorption capacity was also found for the adsorption of BSA on a porous carbon material (i.e., hollow mesoporous carbon). ${ }^{1}$ This is probably related to the hydrophobicity of the m-NpC. Since BSA is highly hydrophilic, it will readily stay in the bulk solution rather than the hydrophobic surface. In contrast, the bilirubin in the BSA-contained solution could be significantly captured by $\mathrm{m}-\mathrm{NpC}$ (see the following sections). These results indicate that the m-NpC has a high selective adsorption ability to compete with albumin for bilirubin binding.
To understand the role of nitrogen doping in the bilirubin adsorption, the bilirubin adsorptions on $\mathrm{m}-\mathrm{NpC}$ and $\mathrm{m}-\mathrm{pC}$ (without nitrogen doping) were conducted. It was found that, under the identical conditions, the adsorption capacity of m$\mathrm{NpC}$ is much higher than that of m-pC (Fig. 5a). Taking into account the surface areas of $\mathrm{m}-\mathrm{NpC}\left(289 \mathrm{~m}^{2} \mathrm{~g}^{-1}\right)$ and $\mathrm{m}-\mathrm{pC}(278$ $\mathrm{m}^{2} \mathrm{~g}^{-1}$ ) are close to each other, it should be inferable that the nitrogen-bonding plays a crucial role in enhancing the adsorption ability of porous carbon adsorbent. In fact, during the recent years, there are a large number of studies reporting the adsorption of acidic molecules by using various nitrogendoped porous carbon materials as adsorbents. ${ }^{25}$ Liu et al. fabricated a nitrogen-doped spherical activated carbon and confirmed that the nitrogen atoms in the carbon skeleton were mainly responsible for the enhancement of the surface basicity and resulted in a high adsorption capacity for uric acid. ${ }^{39}$ Przepiórski reported that the nitrogen-doped activated carbon exhibited a significantly higher adsorption capacity toward phenol than non-doped activated carbon due to the presence of nitrogen in its skeleton. ${ }^{40}$ Given that the bilirubin is a typical acidic molecule containing two carboxylic groups in its molecular structure, it should be rationally concluded that the enhanced adsorption ability of $\mathrm{m}-\mathrm{NpC}$ than $\mathrm{m}-\mathrm{pC}$ is also due to the nitrogen-induced enhancement of surface basicity. Besides, it should be also noted that the m-pC can provides hydrophobic and $\pi-\pi$ interactions ${ }^{5}$ for bilirubin binding and therefore achieves an unnegligible adsorption capacity in spite of the absence of nitrogen atoms in its skeleton (Fig. 5a). In light of the graphite-like nature of $\mathrm{m}-\mathrm{NpC}$, it is likely that the hydrophobic and $\pi-\pi$ interactions are also the driving forces for the adsorption of bilirubin on $\mathrm{m}-\mathrm{NpC}$.

On the basis of the above-mentioned considerations and experimental evidence, a possible adsorption process of bilirubin onto $\mathrm{m}-\mathrm{NpC}$ was proposed (Fig. 5b). In the bilirubin solution, there is a thermodynamic equilibrium between BSAbonded bilirubin and free bilirubin, and the former is the predominant species due to the strong association between bilirubin and BSA. $^{7}$ Upon introduction of $\mathrm{m}-\mathrm{NpC}$ into the solution, the free bilirubin molecules will be gradually adsorbed onto the surface of $\mathrm{m}-\mathrm{NpC}$ driven by the multiple forces including acid-base, hydrophobic, and $\pi-\pi$ interactions. At the same time, new bilirubin molecules will be released from the (a)

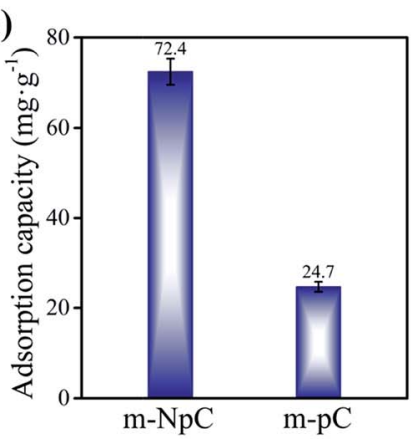

(b)

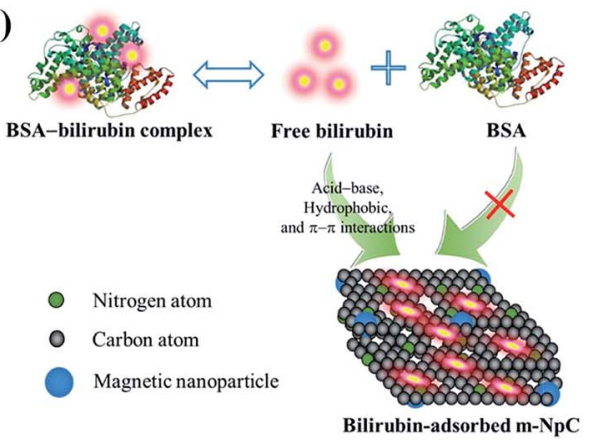

Fig. 5 Comparison of adsorption capacities between $\mathrm{m}-\mathrm{NpC}$ and $\mathrm{m}-\mathrm{pC}$ (mean \pm S.D., $n=3$ ) (a), and a possible adsorption process of BSAbonded bilirubin onto $\mathrm{m}-\mathrm{NpC}$ (b). 
BSA-bilirubin complex in order to maintain the equilibrium of [bilirubin $]_{\text {free }} \leftrightarrow[\text { bilirubin }]_{\text {conjugated }}$. This process will continuously strip bilirubin molecules from the protein conjugate until to reach the adsorption equilibrium. ${ }^{7}$

3.2.2 Isothermal adsorption. Adsorption isotherms are of great significance in the design of adsorption system and allow to estimate the maximum adsorption capacity of adsorbent material. ${ }^{41}$ Moreover, the analysis of the isotherm data by fitting them to different models is an important way to find the suitable model that can provide useful information about the nature of adsorption. ${ }^{41}$

The isothermal experiments of BSA-bonded bilirubin adsorption onto $\mathrm{m}-\mathrm{NpC}$ at different temperatures $(25,30$, and $37{ }^{\circ} \mathrm{C}$ ) were conducted over a range of initial BSA-bonded bilirubin concentrations from 50 to $300 \mathrm{mg} \mathrm{L}^{-1}$. Such a concentration range was chosen on the basis of preliminary tests which showed that, under the experimental conditions used, bilirubin concentration could remain fairly constant, while the bilirubin solutions with higher concentrations (>300 $\mathrm{mg} \mathrm{L}^{-1}$ ) became insufficiently stable. As shown in Fig. 6a, it can be found that the maximum adsorption capacities of $\mathrm{m}-\mathrm{NpC}$ for BSA-bonded bilirubin are $31.0 \mathrm{mg}$ $\mathrm{g}^{-1}$ at $25{ }^{\circ} \mathrm{C}, 41.0 \mathrm{mg} \mathrm{g}^{-1}$ at $30{ }^{\circ} \mathrm{C}$, and $72.4 \mathrm{mg} \mathrm{g}^{-1}$ at $37{ }^{\circ} \mathrm{C}$, respectively. It is generally accepted that adsorption capacity will decrease when the temperature increases. ${ }^{\mathbf{4 2}}$ However, in this work, the adsorption capacity of m-NpC toward BSAbonded bilirubin increase with the increase of temperature (Fig. 6a). In a BSA-rich solution, bilirubin exists primarily in the form of BSA-bilirubin complex. After addition of m-NpC, a part of bilirubin molecules are likely to be released from the BSA-bilirubin complexes through dissociation and then probably captured by m-NpC. At a higher temperature, BSAbilirubin complexes might have a greater tendency to dissociate, which result in an increased number of free bilirubin and thus a higher adsorption capacity of bilirubin onto mNpC. Similar phenomena regarding BSA-bonded bilirubin adsorption were also found over other different adsorbents. ${ }^{7}$

Furthermore, the analysis of the isotherm data by fitting them to two common isotherm models (i.e., Langmuir and Freundlich models) was conducted. The Langmuir and Freundlich isotherm equations can be expressed as follows: ${ }^{41}$
Table 1 Adsorption isotherm constants for BSA-bonded bilirubin adsorption onto $\mathrm{m}-\mathrm{NpC}$

\begin{tabular}{|c|c|c|c|c|}
\hline \multirow[b]{2}{*}{ Isotherm model } & \multirow[b]{2}{*}{ Model parameter } & \multicolumn{3}{|l|}{$T(\mathrm{~K})$} \\
\hline & & 298.15 & 303.15 & 310.15 \\
\hline \multirow[t]{3}{*}{ Langmuir } & $q_{\mathrm{m}}\left(\mathrm{mg} \mathrm{g}^{-1}\right)$ & 105.5 & 591.7 & 714.3 \\
\hline & $K_{\mathrm{L}}\left(\mathrm{L} \mathrm{g}^{-1}\right)$ & 1.15 & 0.26 & 0.39 \\
\hline & $R^{2}$ & 0.3602 & 0.5344 & 0.0635 \\
\hline \multirow[t]{3}{*}{ Freundlich } & $K_{\mathrm{F}}\left(\mathrm{mg}^{1-1 / n} \mathrm{~L}^{1 / n} \mathrm{~g}^{-1}\right)$ & 0.25 & 0.16 & 0.39 \\
\hline & $1 / n$ & 0.821 & 0.986 & 0.919 \\
\hline & $R^{2}$ & 0.9698 & 0.9983 & 0.9871 \\
\hline
\end{tabular}

$$
\begin{gathered}
\frac{1}{q_{\mathrm{e}}}=\frac{1}{q_{\mathrm{m}}}+\frac{1}{K_{\mathrm{L}} q_{\mathrm{m}}} \frac{1}{C_{\mathrm{e}}} \\
\ln q_{\mathrm{e}}=\ln K_{\mathrm{F}}+\frac{1}{n} \ln C_{\mathrm{e}}
\end{gathered}
$$

where $C_{\mathrm{e}}$ is the equilibrium concentration $\left(\mathrm{mg} \mathrm{L}^{-1}\right), q_{\mathrm{e}}$ is the amount of bilirubin adsorbed at equilibrium $\left(\mathrm{mg} \mathrm{g}^{-1}\right), q_{\mathrm{m}}$ is the maximum adsorption capacity $\left(\mathrm{mg} \mathrm{g}^{-1}\right)$, and $K_{\mathrm{L}}\left(\mathrm{L} \mathrm{g}^{-1}\right)$ is the Langmuir isotherm constant; $K_{\mathrm{F}}\left(\mathrm{mg}^{1-1 / n} \mathrm{~L}^{1 / n} \mathrm{~g}^{-1}\right)$ and $1 / n$ (dimensionless) are Freundlich constants, where the $1 / n$ is related to the adsorption intensity.

Fig. 6b shows the resulting plots of Freundlich model by constructing linear plots of $\ln q_{\mathrm{e}}$ versus $\ln C_{\mathrm{e}}$, which are associated with experimental data. The fitting curves of Langmuir model are not shown in Fig. 6b because they seriously deviated from the experimental data. A glance at Fig. $6 \mathrm{~b}$ can leave one the intuitive impression that the experimental data are well represented by the Freundlich model. The obtained fitting parameters and correlation coefficients $\left(R^{2}\right)$ are summarized in Table 1. In all cases, the Freundlich model exhibits high correlation coefficients $\left(0.9698<R^{2}<0.9983\right)$ that are close to 1 , further indicating that the Freundlich model is an appropriate description of the data for bilirubin adsorption on $\mathrm{m}-\mathrm{NpC}$. The constant $1 / n$ values in our experiments are in the range of $0.821-$ 0.986 (Table 1), which are less than 1, implying that these adsorption processes are favorable. ${ }^{43}$ In addition, according to the theoretical assumption of Freundlich model, it can be concluded that the m-NpC has a heterogeneous surface. ${ }^{\mathbf{4 4}}$ (a)

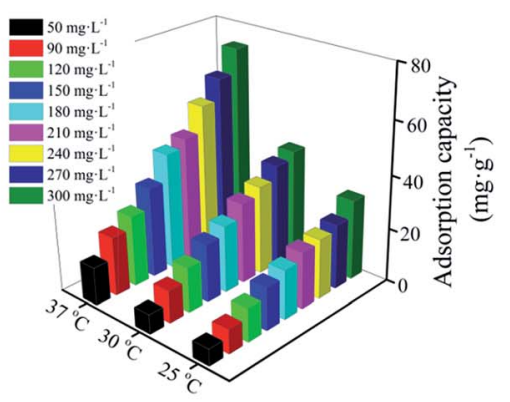

(b)

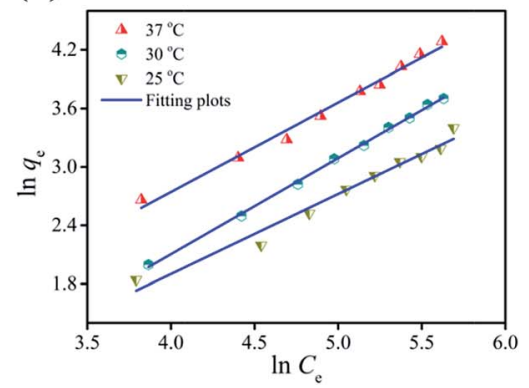

Fig. 6 Effects of temperature and initial concentration on the adsorption capacity of $\mathrm{m}-\mathrm{NpC}$ for BSA-bonded bilirubin (a); fitting of the isothermal adsorption data by Freundlich model (b). 
(a)

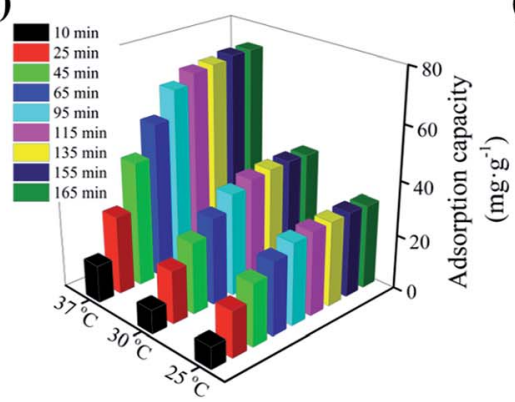

(b)

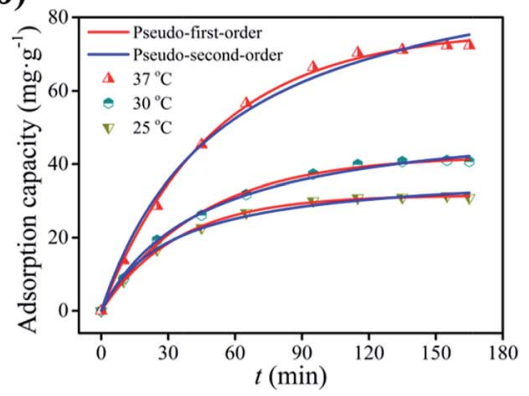

Fig. 7 Effects of temperature and contact time on the adsorption capacity of m-NpC for BSA-bonded bilirubin (a); fitting of the kinetic data by pseudo-first-order and pseudo-second-order models (b).

3.2.3 Adsorption kinetics. Adsorption kinetics is one of the most important characteristics that represent the adsorption efficiency of the adsorbent and, therefore, largely determines the potential applications of adsorbent. ${ }^{44}$ In this study, the kinetic experiments of BSA-boned bilirubin adsorption onto $\mathrm{m}$ NpC were conducted by investigating the adsorption capacity versus the adsorption time at three different temperatures $(25$, 30 , and $37^{\circ} \mathrm{C}$ ), and the results are shown in Fig. 7a. On the whole, the kinetic results also show an increase in adsorption capacity with the increasing temperature during the same time interval. In each case, the adsorption capacity rapidly increases during the initial stage $(\sim 45 \mathrm{~min})$ and then slowly reaches equilibrium within about $115 \mathrm{~min}$. This observation might be explained by the possible successive steps reported widely in the literature for organic molecules adsorption. ${ }^{41}$ Initially, the bilirubin molecules will be preferentially adsorbed on the exterior surface and/or near the pore mouth due to short mass transfer distance and low mass transfer resistance, and then they come to the interior surface of the adsorbent. Therefore, the adsorption capacity increases rapidly first and then slowly with time (Fig. 7a). Compared with the previously reported results, ${ }^{4,45}$ the equilibrium time ( $115 \mathrm{~min})$ is satisfactory, indicating a fast diffusion of bilirubin in the pore channels of m-NpC.

In order to further understand the adsorption process, two most widely used kinetic models (i.e., pseudo-first-order and pseudo-second-order models) were applied to fit the experimental data. The pseudo-first-order and pseudo-second-order equations can be expressed as follows: ${ }^{44}$

$$
\begin{gathered}
q_{t}=q_{\mathrm{e}}\left(1-\mathrm{e}^{-k_{1} t}\right) \\
q_{t}=\frac{k_{2} q_{\mathrm{e}}{ }^{2} t}{1+k_{2} q_{\mathrm{e}} t}
\end{gathered}
$$

where $q_{\mathrm{e}}$ and $q_{t}$ are the adsorption capacities at equilibrium and at time $t$, respectively $\left(\mathrm{mg} \mathrm{g}^{-1}\right), k_{1}$ is the rate constant of pseudofirst-order adsorption $\left(\mathrm{min}^{-1}\right), k_{2}$ is the rate constant of pseudosecond-order adsorption $\left(\mathrm{g} \mathrm{mg}^{-1} \mathrm{~min}^{-1}\right)$.

As shown in Fig. 7b, the pseudo-first-order model provides a better fit to the experimental data than the pseudo-secondorder one. Values of the two kinetic model constants $\left(k_{1}\right.$ and $\left.k_{2}\right)$, calculated equilibrium adsorption capacities $\left(q_{\mathrm{e}, \mathrm{calc}, 1}\right.$ and $\left.q_{\mathrm{e}, \text { calc, } 2}\right)$, along with correlation coefficients $\left(R^{2}\right)$ are summarized in Table 2. It is evident that in all cases the $R^{2}$ values $\left(0.9982<R^{2}\right.$ $<0.9993)$ are closer to unity for the pseudo-first-order equation, which are slightly higher than those $\left(0.9936<R^{2}<0.9966\right)$ for the pseudo-second-order equation, indicating that the bilirubin adsorption onto $\mathrm{m}-\mathrm{NpC}$ can be described more appropriately by the pseudo-first-order model. Moreover, the calculated equilibrium adsorption capacities $\left(q_{\mathrm{e}, \text { calc, } 1}\right)$ using the pseudo-firstorder model are pretty close to the experimental values (Table 2), which also confirms the suitability of this model.

3.2.4 Comparison of adsorption capacities between different adsorbents. A comparison between $\mathrm{m}-\mathrm{NpC}$ and some other previously reported adsorbents for removal of free bilirubin and albumin-bonded bilirubin from aqueous solution was conducted and the results are summarized in Table $3^{1,4,8-10,46-52}$ The adsorption capacity value of $\mathrm{m}-\mathrm{NpC}$ at $37^{\circ} \mathrm{C}$ is applied to compare with those obtained by other adsorbents according to the fact that the removal of bilirubin, in practice, is generally performed at this temperature (normal body temperature). It can be found that the $\mathrm{m}-\mathrm{NpC}$ shows a high efficiency for the adsorption of BSA-boned bilirubin and the adsorption capacity is much higher than those obtained by other adsorbents presented in Table 3 . Moreover, the adsorption capacity of $\mathrm{m}-\mathrm{NpC}$ is even higher than those of many reported adsorbents toward free bilirubin. The difference in adsorption capacity

\begin{tabular}{|c|c|c|c|c|c|c|c|}
\hline \multirow[b]{2}{*}{$T(\mathrm{~K})$} & \multirow[b]{2}{*}{$q_{\mathrm{e}, \exp }\left(\mathrm{mg} \mathrm{g}^{-1}\right)$} & \multicolumn{3}{|c|}{ Pseudo-first-order model } & \multicolumn{3}{|c|}{ Pseudo-second-order model } \\
\hline & & $k_{1}\left(\min ^{-1}\right)$ & $q_{\mathrm{e}, \mathrm{cal}, 1}\left(\mathrm{mg} \mathrm{g}^{-1}\right)$ & $R^{2}$ & $k_{2}\left(\mathrm{~g} \mathrm{mg}^{-1} \min ^{-1}\right)$ & $q_{\mathrm{e}, \mathrm{cal}, 2}\left(\mathrm{mg} \mathrm{g}^{-1}\right)$ & $R^{2}$ \\
\hline 298.15 & 31.0 & 0.02923 & 31.6 & 0.9993 & 0.00082 & 38.4 & 0.9944 \\
\hline 303.15 & 41.0 & 0.02259 & 42.3 & 0.9982 & 0.00041 & 53.7 & 0.9966 \\
\hline 310.15 & 72.4 & 0.02023 & 76.4 & 0.9985 & 0.00018 & 100.1 & 0.9936 \\
\hline
\end{tabular}

Table 2 Adsorption kinetic constants for BSA-bonded bilirubin adsorption onto m-NpC 
Table 3 Comparison of adsorption capacities between different adsorbents

\begin{tabular}{|c|c|c|c|}
\hline Adsorbent & Adsorbate & $\begin{array}{l}\text { Adsorption capacity } \\
\left(\mathrm{mg} \mathrm{g}^{-1}\right)\end{array}$ & Ref. \\
\hline BSA-modified silica & Free bilirubin & 1.655 & 46 \\
\hline Polymer coated silica & Free bilirubin & 43.47 & 51 \\
\hline Functional polyethersulfone particles & Free bilirubin & 38.03 & 52 \\
\hline Millimetre-sized mesoporous carbon spheres & Free bilirubin & 148.4 & 10 \\
\hline Heparin-modified chitosan/graphene oxide & BSA-bonded bilirubin & 8.96 & 4 \\
\hline Carbon nanotube sheets & BSA-bonded bilirubin & 9.7 & 8 \\
\hline Oxidized single-wall carbon nanohorns & BSA-bonded bilirubin & 12 & 9 \\
\hline Grafted polytetrafluoroethylene fibers & BSA-bonded bilirubin & 8 & 50 \\
\hline Hollow mesoporous carbon sphere & BSA-bonded bilirubin & 31.28 & 1 \\
\hline $\mathrm{m}-\mathrm{NpC}$ & BSA-bonded bilirubin & 72.4 & This study \\
\hline
\end{tabular}

should mainly contribute to the texture parameters (e.g., specific surface area) and surface properties of adsorbents. Benefitting from the highly porous structure, high specific surface area, large pore volume and, in particular, unique basic sites-rich surface, the m-NpC shows a superior adsorption efficiency for albumin-bonded bilirubin. Moreover, compared with most of the reported bilirubin adsorbents, the m-NpC has an obvious advantage that it can be easily and rapidly retrieved by an external magnet without the need of additional centrifugation or filtration, greatly facilitating the separation process.

\subsection{Hemolysis assay}

During hemoperfusion, it is inevitable for solid adsorbent to make a contact with blood. This leads to the necessity for blood compatibility study of adsorbent. Human blood is composed of blood cells $(45 \%, \mathrm{v} / \mathrm{v})$ and blood plasma $(55 \%, \mathrm{v} / \mathrm{v})$, and the latter is essentially an aqueous solution containing $92 \%$ water and $8 \%$ plasma proteins, so the interaction between adsorbent with blood cells are particularly important. ${ }^{53}$ In this study, we

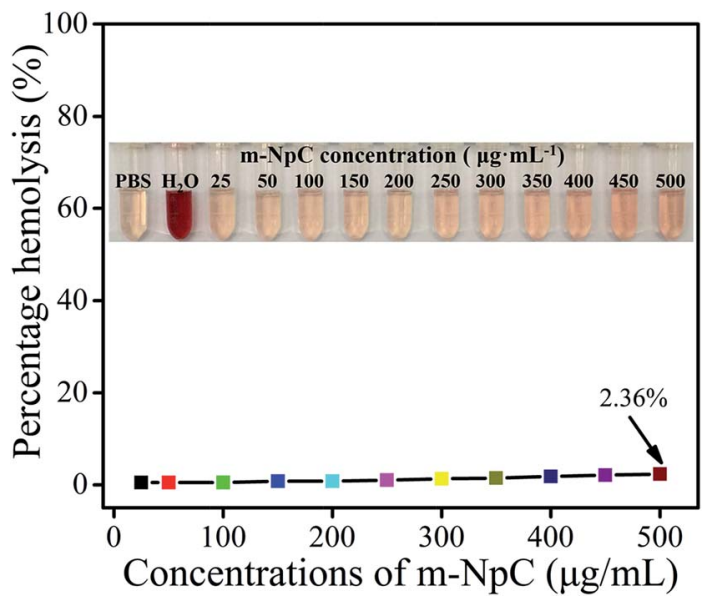

Fig. 8 Effect of the $\mathrm{m}-\mathrm{NpC}$ dosage on the hemolysis rate. The inset shows the photographs of RBCs incubated with different amount of $\mathrm{m}-\mathrm{NpC}$, where water and PBS were used as positive and negative controls, respectively. therefore conducted the hemolysis assay experiments to evaluate the blood compatibility of $\mathrm{m}-\mathrm{NpC}$ according to a previously reported procedure. ${ }^{1}$ A series of red blood cells (RBCs) suspensions $(0.3 \mathrm{~mL})$ were mixed $1.2 \mathrm{~mL}$ of PBS followed by addition of different amount of m-NpC. As a control group, the positive and negative samples were also prepared by mixing 0.3 $\mathrm{mL}$ of RBCs suspensions with $1.2 \mathrm{~mL}$ of deionized water and 1.2 $\mathrm{mL}$ of PBS, respectively. It is well known that the RBCs are red in color due to the presence of hemoglobin in the cells. During the hemolysis assay experiments, hemoglobin will be released into the solution once hemolysis occurs, thereby making the solution turn red. The hemolytic activity is proportional to the released amount of hemoglobin, which can be determined by UV-vis spectroscopy with an absorbance intensity of $541 \mathrm{~nm}^{.33}$ Based on these considerations, we examined the hemolytic activity of m-NpC. Fig. 8 shows the photographs of RBCs solutions after incubated with $\mathrm{m}-\mathrm{NpC}$ suspensions for $2 \mathrm{~h}$. No significant hemolysis phenomenon can be observed visually even at the highest $\mathrm{m}$-NpC usage $\left(500 \mu \mathrm{g} \mathrm{mL} \mathrm{m}^{-1}\right)$. From Fig. 8 , it is also observed that the calculated hemolysis rate at this point is quite low $(<2.36 \%)$. The results suggest excellent hemocompatibility of $\mathrm{m}-\mathrm{NpC}$ according to the standard acceptance limit (less than $5 \%{ }^{54}$ ). In light of the fact that the highest dose of $\mathrm{m}-\mathrm{NpC}$ in the hemolysis assay is much higher than that used in our adsorption experiments $\left(300 \mu \mathrm{g} \mathrm{mL} \mathrm{m}^{-1}\right)$, the adsorbent should be fairly safe to blood purification application.

\section{Conclusions}

In summary, we reported a facile strategy for one-pot synthesis of magnetic nitrogen-doped porous carbon (m-NpC) and demonstrated its superior adsorption properties for BSA-boned bilirubin removal. The proposed synthesis method is simple, low cost, scalable, and will not produce any toxic substances. The resulting $\mathrm{m}$-NpC showed a hierarchically micro-mesomacroporous structure, high specific surface area $\left(289 \mathrm{~m}^{2} \mathrm{~g}^{-1}\right)$, and large pore volume $\left(0.33 \mathrm{~cm}^{3} \mathrm{~g}^{-1}\right)$. Moreover, the basic sitesrich surface of $\mathrm{m}-\mathrm{NpC}$ obtained as a result of nitrogen doping could compete effectively with albumin for bilirubin binding. In 
addition, the as-prepared $\mathrm{m}-\mathrm{NpC}$ was found to be well dispersed in water and could be easily separated from the medium just by addition of an external magnet. Under optimized conditions, bilirubin adsorption reached equilibrium within about $115 \mathrm{~min}$, and the maximum adsorption capacity could be up to $72.4 \mathrm{mg} \mathrm{g}^{-1}$ at $37^{\circ} \mathrm{C}$, which is significantly higher than those of various previously reported bilirubin adsorbents. Isotherm modeling confirmed that the Freundlich equation could satisfyingly describe the adsorption process of bilirubin onto $\mathrm{m}-\mathrm{NpC}$ from BSA-contained solution, while fitting of kinetic data revealed that the pseudo-first-order model matched well with the experimental data. In addition, the hemolysis assays showed that this adsorbent $\left(500 \mu \mathrm{g} \mathrm{mL}^{-1}\right)$ had only a negligible hemolysis effect with a hemolysis rate less than $2.36 \%$. The magnetic nitrogen-doped hierarchical porous carbon developed in this work can be used as a promising adsorbent for removal of protein-bonded bilirubin.

\section{Acknowledgements}

This work was supported by the National Natural Science Foundation of China (No. 21303170), Natural Science Foundation of Hubei Province (No. 2015CFB187), and the Fundamental Research Funds for the Central Universities, China University of Geosciences (Wuhan) (No. CUGL150414, CUGL140413 and CUG120115).

\section{References}

1 L. M. Guo, L. X. Zhang, J. M. Zhang, J. Zhou, Q. J. He, S. Z. Zeng, X. Z. Cui and J. L. Shi, Chem. Commun., 2009, 6071-6073.

2 S. K. Chou and M. J. Syu, Biomaterials, 2009, 30, 1255-1262. 3 G. Baydemir, M. Andaç, N. Bereli, R. Say and A. Denizli, Ind. Eng. Chem. Res., 2007, 46, 2843-2852.

4 H. L. Wei, L. L. Han, Y. C. Tang, J. Ren, Z. B. Zhao and L. Y. Jia, J. Mater. Chem. B, 2015, 3, 1646-1654.

5 K. Shinke, K. Ando, T. Koyama, T. Takai, S. Nakaji and T. Ogino, Colloids Surf., B, 2010, 77, 18-21.

6 B. R. Müller, Carbon, 2010, 48, 3607-3615.

7 H. L. Wei, L. Xu, J. Ren and L. Y. Jia, Colloids Surf., A, 2012, 405, 38-44.

8 K. Ando, K. Shinke, S. Yamada, T. Koyama, T. Takai, S. Nakaji and T. Ogino, Colloids Surf., B, 2009, 71, 255-259.

9 K. Yamazak, K. Shinke and T. Ogino, Colloids Surf., B, 2013, 112, 103-107.

10 L. M. Guo, J. M. Zhang, Q. J. He, L. X. Zhang, J. J. Zhao, Z. Y. Zhu, W. Wu, J. Zhang and J. L. Shi, Chem. Commun., 2010, 46, 7127-7129.

11 L. M. Guo, X. Z. Cui, Y. S. Li, Q. J. He, L. X. Zhang, W. B. Bu and J. L. Shi, Chem.-Asian J., 2009, 4, 1480-1485.

12 G. J. Tao, L. X. Zhang, Z. L. Hua, Y. Chen, L. M. Guo, J. M. Zhang, Z. Shu, J. H. Gao, H. R. Chen, W. Wu, Z. W. Liu and J. L. Shi, Carbon, 2014, 66, 547-559.

13 K. I. Yamamoto, K. Eguchi, I. Kaneko, T. Akiba and M. Mineshima, Blood Purif., 2013, 35, 51-54.
14 J. Ju, G. H. He, Z. J. Duan, W. Zhao, Y. F. Liu, L. L. Zhang and Y. H. Li, Biochem. Eng. J., 2013, 79, 144-152.

15 A. V. Solomonov, E. V. Rumyantsev, S. P. Ivanov, B. A. Kochergin and E. V. Antina, Protein J., 2013, 32, 343355.

16 T. Chandy and C. P. Sharma, J. Microencapsulation, 1993, 10, 475-486.

17 A. Ouyang, Q. Gong and J. Liang, Adv. Eng. Mater., 2015, 17, 460-466.

18 E. H. Dunlop, R. D. Hughes and R. Williams, Med. Biol. Eng. Comput., 1978, 16, 343-349.

19 Z. Yang, H. G. Nie, X. A. Chen, X. H. Chen and S. M. Huang, J. Power Sources, 2013, 236, 238-249.

20 S. L. Candelaria, B. B. Garcia, D. Liu and G. Z. Cao, J. Mater. Chem., 2012, 22, 9884-9889.

21 L. J. Yang, S. J. Jiang, Y. Zhao, L. Zhu, S. Chen, X. Z. Wang, Q. Wu, J. Ma, Y. W. Ma and Z. Hu, Angew. Chem., Int. Ed., 2011, 123, 7270-7273.

22 Z. S. Qian, X. Y. Shan, L. J. Chai, J. J. Ma, J. R. Chen and H. Feng, ACS Appl. Mater. Interfaces, 2014, 6, 6797-6805.

23 R. L. Liu, W. J. Ji, T. He, Z. Q. Zhang, J. Zhang and F. Q. Dang, Carbon, 2014, 76, 84-95.

24 D. S. Yang, D. Bhattacharjya, S. Inamdar, J. Park and J. S. Yu, J. Am. Chem. Soc., 2012, 134, 16127-16130.

25 W. Z. Shen and W. B. Fan, J. Mater. Chem. A, 2013, 1, 9991013.

26 G. D. Yang, L. Tang, G. M. Zeng, Y. Cai, J. Tang, Y. Pang, Y. Y. Zhou, Y. Y. Liu, J. J. Wang, S. Zhang and W. P. Xiong, Chem. Eng. J., 2015, 259, 854-864.

27 X. Q. Fan, L. X. Zhang, G. B. Zhang, Z. Shu and J. L. Shi, Carbon, 2013, 61, 423-430.

28 M. Y. Zhu and G. W. Diao, Nanoscale, 2011, 3, 2748-2767.

29 L. K. Komissarova, A. A. Kuznetsov, N. P. Gluchoedov, M. V. Kutushov and M. A. Pluzan, J. Magn. Magn. Mater., 2001, 225, 197-201.

30 N. Fechler, T. P. Fellinger and M. Antonietti, Adv. Mater., 2013, 25, 75-79.

31 C. N. He, S. Wu, N. Q. Zhao, C. S. Shi, E. Z. Liu and J. J. Li, ACS Nano, 2013, 7, 4459-4469.

32 Y. Li, Q. Meng, S. M. Zhu, Z. H. Sun, H. Yang, Z. X. Chen, C. L. Zhu, Z. P. Guo and D. Zhang, Dalton Trans., 2015, 44, 4594-4600.

33 Q. Liu, Y. X. Duan, Q. P. Zhao, F. P. Pan, B. Zhang and J. Y. Zhang, Langmuir, 2014, 30, 8238-8245.

34 H. M. Sun, W. H. He, C. H. Zong and L. H. Lu, ACS Appl. Mater. Interfaces, 2013, 5, 2261-2268.

35 M. Sevilla and A. B. Fuertes, ACS Nano, 2014, 8, 5069-5078. 36 K. S. Xia, X. L. Tian, S. X. Fei and K. You, Int. J. Hydrogen Energy, 2014, 39, 11047-11054.

37 L. Chen, K. S. Xia, L. Z. Huang, L. W. Li, L. B. Pei and S. X. Fei, Int. J. Hydrogen Energy, 2013, 38, 3297-3303.

38 G. Leofanti, M. Padovan, G. Tozzola and B. Venturelli, Catal. Today, 1998, 41, 207-219.

39 C. J. Liu, X. Y. Liang, X. J. Liu, Q. Wang, L. Zhan, R. Zhang, W. M. Qiao and L. C. Ling, Appl. Surf. Sci., 2008, 254, 6701-6705.

40 J. Przepiórski, J. Hazard. Mater., 2006, 135, 453-456. 
41 Q. Gao, H. Zhu, W. J. Luo, S. Wang and C. G. Zhou, Microporous Mesoporous Mater., 2014, 193, 15-26.

42 W. J. Luo, Q. Gao, X. L. Wu and C. G. Zhou, Sep. Sci. Technol., 2014, 49, 2400-2411.

43 B. H. Hameed, A. A. Ahmad and N. Aziz, Chem. Eng. J., 2007, 133, 195-203.

44 S. Wang, Y. Y. Zhai, Q. Gao, W. J. Luo, H. Xia and C. G. Zhou, J. Chem. Eng. Data, 2014, 59, 39-51.

45 T. Tang, X. A. Li, Y. Xu, D. Wu, Y. H. Sun, J. Xu and F. Deng, Colloids Surf., B, 2011, 84, 571-578.

46 A. Timin, E. Rumyantsev and A. Solomonov, J. Non-Cryst. Solids, 2014, 385, 81-88.

47 Z. Wang, Y. M. Cao, H. L. Wei, L. Y. Jia, L. Xu and J. Xie, Colloids Surf., B, 2012, 90, 248-253.
48 Z. W. Ma, M. Kotaki and S. Ramakrishna, J. Membr. Sci., 2005, 265, 115-123.

49 L. X. Zhang, M. Zhu, L. M. Guo, L. Li and J. L. Shi, NanoMicro Lett., 2009, 1, 14-18.

50 X. Y. Han and Z. P. Zhang, Polym. Int., 2009, 58, 1126-1133.

51 A. S. Timin, S. Y. Khashirova, A. Zhansitov and E. V. Rumyantsev, Colloid Polym. Sci., 2015, 293, 1667-1674.

52 X. Jiang, T. Xiang, Y. Xie, R. Wang, W. F. Zhao, S. D. Sun and C. S. Zhao, J. Mater. Sci., DOI: 10.1007/s10856-015-5642-9.

53 Z. J. Ding, Z. J. Zhang, H. W. Ma and Y. Y. Chen, ACS Appl. Mater. Interfaces, 2014, 6, 19797-19807.

54 M. Akrami, M. Khoobi, M. Khalilvand-Sedagheh, I. Haririan, A. Bahador, M. A. Faramarzi, S. Rezaei, H. A. Javar, F. Salehi, S. S. Ardestani and A. Shafiee, RSC Adv., 2015, 5, 8809688107. 